\title{
Does Mammotome biopsy affect surgery option and margin status of breast conserving surgery in breast cancer?
}

\author{
Yanan Kong ${ }^{1 \#}$, Ning Lyu ${ }^{2 \#}$, Jianwei Wang ${ }^{3}$, Yan Wang ${ }^{1}$, Ya Sun ${ }^{1}$, Zeming Xie ${ }^{1}$, Peng Liu ${ }^{1}$ \\ ${ }^{1}$ Department of Breast Oncology, Sun Yat-sen University Cancer Center, State Key Laboratory of Oncology in South China, Collaborative \\ Innovation Center for Cancer Medicine, Guangzhou, China; ${ }^{2}$ Department of Minimally Invasive Interventional Radiology, Sun Yat-sen University \\ Cancer Center, State Key Laboratory of Oncology in South China, Collaborative Innovation Center for Cancer Medicine, Guangzhou, China; \\ ${ }^{3}$ Department of Ultrasound, Sun Yat-sen University Cancer Center, State Key Laboratory of Oncology in South China, Collaborative Innovation \\ Center for Cancer Medicine, Guangzhou, China \\ Contributions: (I) Conception and design: Y Kong, N Lyu, P Liu; (II) Administrative support: P Liu; (III) Provision of study materials or patients: J \\ Wang; (IV) Collection and assembly of data: Y Kong, Y Wang, Y Sun; (V) Data analysis and interpretation: Y Kong, N Lyu; (VI) Manuscript writing: \\ All authors; (VII) Final approval of manuscript: All authors. \\ \#These authors contributed equally to this work. \\ Correspondence to: Yanan Kong, MD. Department of Breast Oncology, Sun Yat-sen University Cancer Center, State Key Laboratory of Oncology in South \\ China, Collaborative Innovation Center for Cancer Medicine, 651 Dongfeng Road East, Guangzhou 510060, China. Email: kongyn@sysucc.org.cn; \\ Peng Liu, MD. Department of Breast Oncology, Sun Yat-sen University Cancer Center, State Key Laboratory of Oncology in South China, Collaborative \\ Innovation Center for Cancer Medicine, 651 Dongfeng Road East, Guangzhou 510060, China. Email: liupeng@sysucc.org.cn.
}

Background: The Mammotome, an image-guided, usually ultrasound-guided vacuum-assisted breast biopsy (US-VABB) system, has been widely used in the early diagnosis of breast disease and the complete excision of benign lesions. However, in some malignant lesions underestimated by U.S., whether Mammotome biopsy would affect the surgery option, especially the margin status in breast-conserving surgery (BCS), has never been studied.

Methods: Between 2015 and 2019, 198 patients with 200 lesions who have been diagnosed with breast cancer by Mammotome elsewhere received surgery by pathological confirmation in our center. The clinicopathological characteristics, surgery options, therapies, and the details of the specimen, such as margin status of BCS, tumor residual after VABB, and hematoma were reviewed.

Results: Among 200 lesions, 90\% were evaluated below US-BIRADS 4b before Mammotome biopsy and $94.5 \%$ with a tumor size $\leq 3 \mathrm{~cm} .131$ patients received mastectomy (66.2\%) and 67 received BCS (33.8\%). Hematoma and tumor residual were observed in $37.5 \%$ and $71.5 \%$ of all lesions, respectively. There is a higher incidence of hematoma in the mastectomy group than in the BCS group (44.4\% vs. 23.9\%, $\mathrm{P}=0.005)$. In BCS group, the positive margin was found in 7 patients at first examination including four focals with reexcision, two extensive with mastectomy and one focal but refusing further surgery. The ultimate success rate of BCS was $95.5 \%$. Margin positivity correlated with tumor residual $(\mathrm{P}=0.044)$ but not with hematoma.

Conclusions: Mammotome biopsy might lead to hematoma and tumor residual; however, it is not the determinant factor for a surgery option, and BCS is feasible through a complete excision of tumor residual to acquire negative margin.

Keywords: Mammotome; breast-conserving surgery (BCS); margin status; breast cancer

Submitted Sep 07, 2020. Accepted for publication Jul 02, 2021.

doi: 10.21037 /gs-20-701

View this article at: https://dx.doi.org/10.21037/gs-20-701 


\section{Introduction}

Minimally invasive biopsy tests have been widely used in the early diagnosis of breast lesions in recent years, including needle-biopsies and image (ultrasound/mammography/ magnetic resonance imaging)-guided vacuum-assisted systems $(1,2)$. Ultrasound-guided vacuum-assisted (USVA) system is the most common used method clinically. Compared with open surgical biopsy, these techniques take low costs, bring well tolerance and leave almost indiscoverable scars, at the same time guarantee remarkable high sensitivity and specificity (3). There are a variety of studies suggesting that compared with fine-needle aspiration cytology and core needle biopsy, US-VA breast biopsy (US-VABB) could significantly further increase the diagnostic accuracy (4-8). Moreover, by the assistance of the US-VABB biopsy system, benign lesions can be excised completely, with less injury to its surrounding normal tissue and avoiding residual tissues in most cases (8). Therefore, currently, US-VABB is recommended as a standard of care in breast lesions management by several guidelines (9). For benign lesions, US-VABB is usually used for a complete excision $(10,11)$, while in cases of malignancy that was underestimated by the U.S., though acquired a pathological diagnosis, US-VABB may lead to the residual and even spread of malignancy.

The Mammotome, a ultrasound/mammography/ magnetic resonance imaging-guided, usually ultrasoundguided VABB system, was first introduced in the diagnosis of breast disease in the 1990s (12). This system is easy to master and can be performed in the outpatient setting. In the clinical practice, we found that some patients come to our center for surgery who have been diagnosed with breast cancer by Mammotome in other hospitals before. Most of them were evaluated by the U.S. at BI-RADS 3 or 4A, which always indicates benign lesions before the biopsy, but with the final pathological confirmation of malignancy. As we all know, different from a complete excision, the tissues are cut into several pieces in the breast during the procedure of Mammotome, which may lead to residual malignant cells in split tissues or blood from broken vessels. In this scenario, the way of surgery should be considered with discretion to achieve both safety and beauty. Whether Mammotome biopsy will affect the surgeries, especially the margin status in BCS, is still unknown and has never been studied before.

This study retrospect 200 lesions from 198 patients with breast cancer who were diagnosed by ultrasound- guided Mammotome elsewhere and received surgeries in our cancer center between 2015 and 2019, to evaluate the impact of Mammotome biopsy on the choice of surgery, particularly, the impact on the margin status in those who underwent breast-conserving surgery (BCS). We present the following article in accordance with the STROBE reporting checklist (available at https://dx.doi. org/10.21037/gs-20-701).

\section{Methods}

\section{Patient}

This retrospective study was conducted following the principles of the Declarations of Helsinki and was approved by the institutional review board of the study cancer center. Informed consent was obtained from all patients before the surgery. From a prospectively maintained electronic database at the center from January 2015 to December 2019, patients with breast tumor who underwent percutaneous lesion biopsy by using the US-VA systemguided Mammotome procedure in other hospitals were reviewed. The 8 -gauge Mammotome biopsy system (Johnson \& Johnson; Ethicon Endo-Surgery, Cincinnati, $\mathrm{OH})$ is the most common used in these cases. All patients were consecutively included.

We obtained two hundred patients with 202 lesions registered in the database. Two patients were diagnosed with simultaneously bilateral invasive ductal carcinoma. All sections of the lesion specimens in other hospitals were reevaluated and diagnosed by the pathologist of the study center. Of the 202 lesions, each one of two patients was pathologically confirmed as non-malignant tumors (one as ductal papilloma and one as atypical ductal hyperplasia) before surgery. Finally, 198 patients with 200 lesions received surgery for breast cancer.

\section{Clinic-pathological and therapeutic data collection}

All breast lesions were examined by both mammography and US, and the screening results were reported as follows: "incomplete evaluation" (class 0), "negative" (class 1), "benign lesion" (class 2), "probably benign lesion" (class 3), "low suspicious for malignant lesion" (class 4A), "moderate suspicious for malignant lesion" (class 4B), "high suspicious for malignant lesion" (class 4C), and "highly suggestive malignant lesion" (class 5), based on the evaluation classification of the American College of 
Radiology Breast Imaging Reporting and Data System (BI-RADS), 5th edition (13). Diseases for malignant breast lesions were staged according to the American Joint Committee on Cancer (AJCC) 8th edition. Molecular subtype was categorized using the combination of the immunohistochemical definition of estrogen receptor (ER) and progesterone receptor (PR), overexpression and/ or amplification of the human epidermal growth factor receptor 2 (HER2) gene, and Ki-67 proliferated index (14). Briefly, each lesion was classified as the following subtype: "Luminal A" [ER and/or PR positive, HER2 negative, and Ki-67 low ( $\leq 14 \%)$ ], "Luminal B" (ER and/or PR positive, HER2 overexpressed or amplified, and any Ki-67) or [ER and/or PR positive, HER2 negative, and Ki-67 high $(>14 \%)$ ], "HER2 enriched" (ER and/or PR negative, HER2 overexpressed or amplified, and any Ki-67), or "triple negative breast cancer (TNBC)" (ER, PR, and HER2 negative, and any Ki-67).

The principle of the treatment strategy for patients with breast cancer referred to National Comprehensive Cancer Network (NCCN) guidelines (15). For patients with clinical T1-3, N0-1, M0 stage, surgery was recommended as the first choice. For those inoperable tumors or with desire for BCS, preoperative systemic therapy (neoadjuvant therapy) was performed first. Surgery options were determined by both the tumor situation and the patients' willingness. NCCN listed the absolute and relative contradictions for BCS, and for those who were not the appropriate candidates but had a strong desire for shape, breast construction would recommend to them along with the information of risks.

\section{Statistical analysis}

Continuous variables were shown as median with range, and categorical variables were shown as a number with a percentage. Differences in continuous variables among groups were tested using a $t$-test, and differences in categorical variables were tested using a chi-squared or Fisher's exact test. Univariate analysis was performed by using logistic binary regression analysis. Alpha was set at 0.05 , and all tests were two-tailed. The analytical processing was conducted by SPSS version 25.0 (Chicago, IL, USA). All data were recorded at the Research Data Deposit (RDD) platform of Sun Yat-sen University Cancer Center (http://www.researchdata.org.cn/; ID: RDDA2020001459).

\section{Results}

\section{BI-RADS classification and tumor size before Mammotome biopsy}

All two hundred breast lesions from 198 patients had been evaluated by ultrasound before Mammotome biopsy in other hospitals. Breast imaging reporting and assessing system (from 0-6) was used as the standard to describe the possibility of a malignancy. We found that BI-RADS 3 was the most common classification, accounting for $54 \%(108 / 200)$ of 200 lesions and followed by BI-RADS $4 \mathrm{a}(35 \%), 4 \mathrm{~b}(6 \%), 4 \mathrm{c}(3 \%)$ and $2(1 \%)$. There were $90 \%$ $(180 / 200)$ of the lesions below a classification of BI-RADS 4B. The ultrasound before Mammotome also showed that the tumor size $\leq 3 \mathrm{~cm}$ was observed in 189 lesions, accounting for a percentage of $94.5 \%$. There were two lesions with only calcifications and four lesions with tumor size $>5 \mathrm{~cm}$. There was no significant difference in BI-RADS and tumor size between the mastectomy group $(\mathrm{P}=0.382)$ and the $\mathrm{BCS}$ group $(\mathrm{P}=0.448)$ (Table 1).

\section{Clinic-pathological characteristics and therapies based on surgery options}

The mean age of 198 patients who undergone Mammotome biopsy and surgery was $42.9 \pm 9.5$ (range, 24-73). Breast cancer with stage 0 , I, II, and III accounted for $19.5 \%$, $55.5 \%, 20.5 \%$ and $4.5 \%$ of all, respectively. Carcinoma in situ was observed in $19 \%$ of lesions, and the details of histology were shown in Figure 1. A percentage of $79.5 \%$ of tumors were ER positive, and $15.5 \%$ were HER2 positive. There were $10 \%$ of tumors classified into the TNBC subtype. One hundred and thirty-one patients with 133 lesions received mastectomy and 67 patients received BCS. The details of all surgical options were shown in Figure 2. To achieve the patients' requirements for shape, 12 patients received skin-spared mastectomy combined with implantation in mastectomy group and 5 patients received BCS combined dorsal muscle flap construction in BCS group. One patient only received lumpectomy due to the pathological diagnosis of pleomorphic LCIS according to AJCC 8th. Clinic-pathological characteristics and therapies total/based on surgery options were showed in Table 1 . The mean age of patients in BCS group was younger than that in mastectomy group (39.2 vs. 44.8, $\mathrm{P}<0.001)$. More patients received radiotherapy in BCS group than that mastectomy group ( $83.6 \%$ vs. $12.8 \%, \mathrm{P}<0.001)$. There was no difference 
Table 1 Clinic-pathological characteristics of patients with breast tumor resected by Mammotome

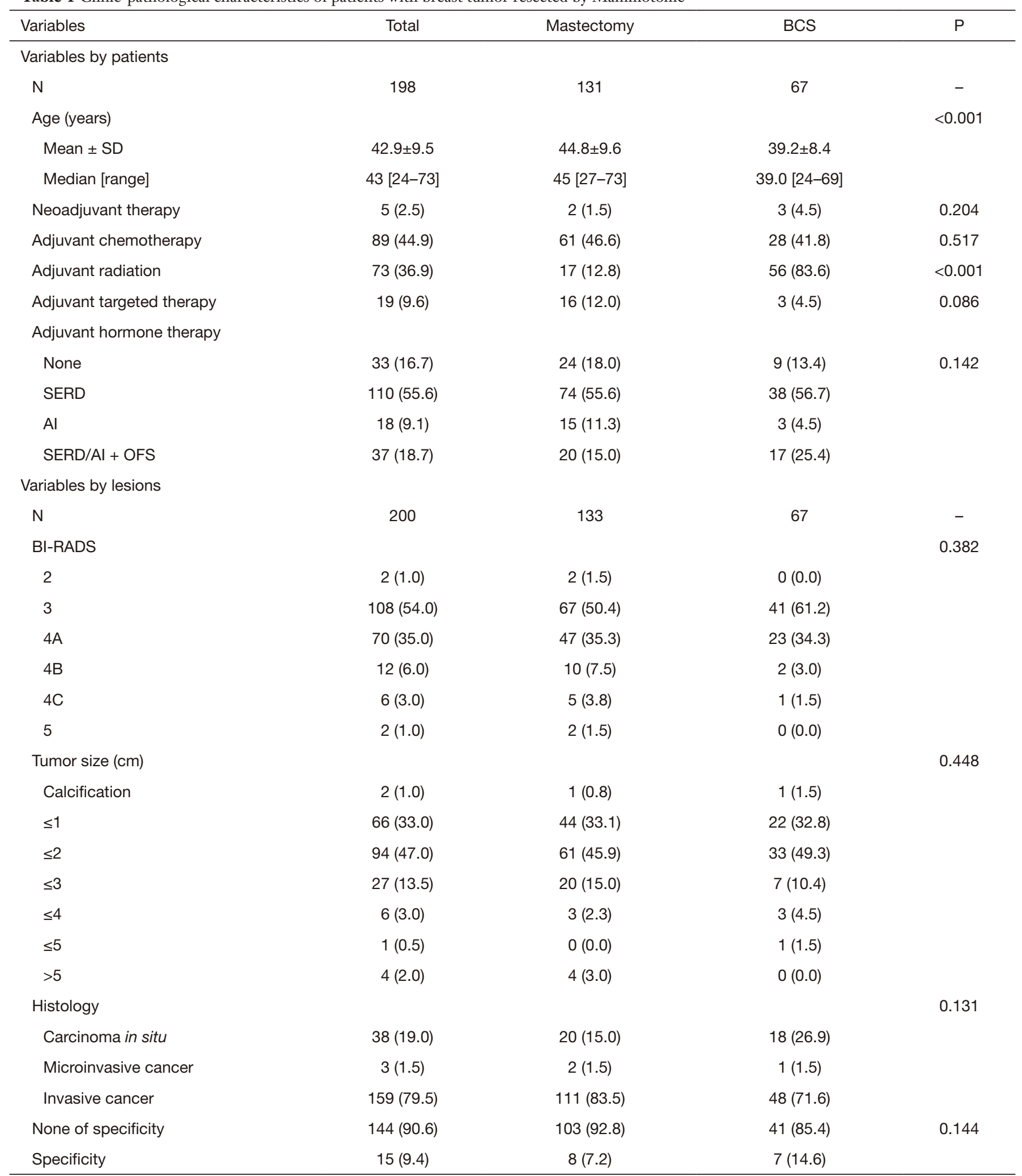

Table 1 (continued) 
Table 1 (continued)

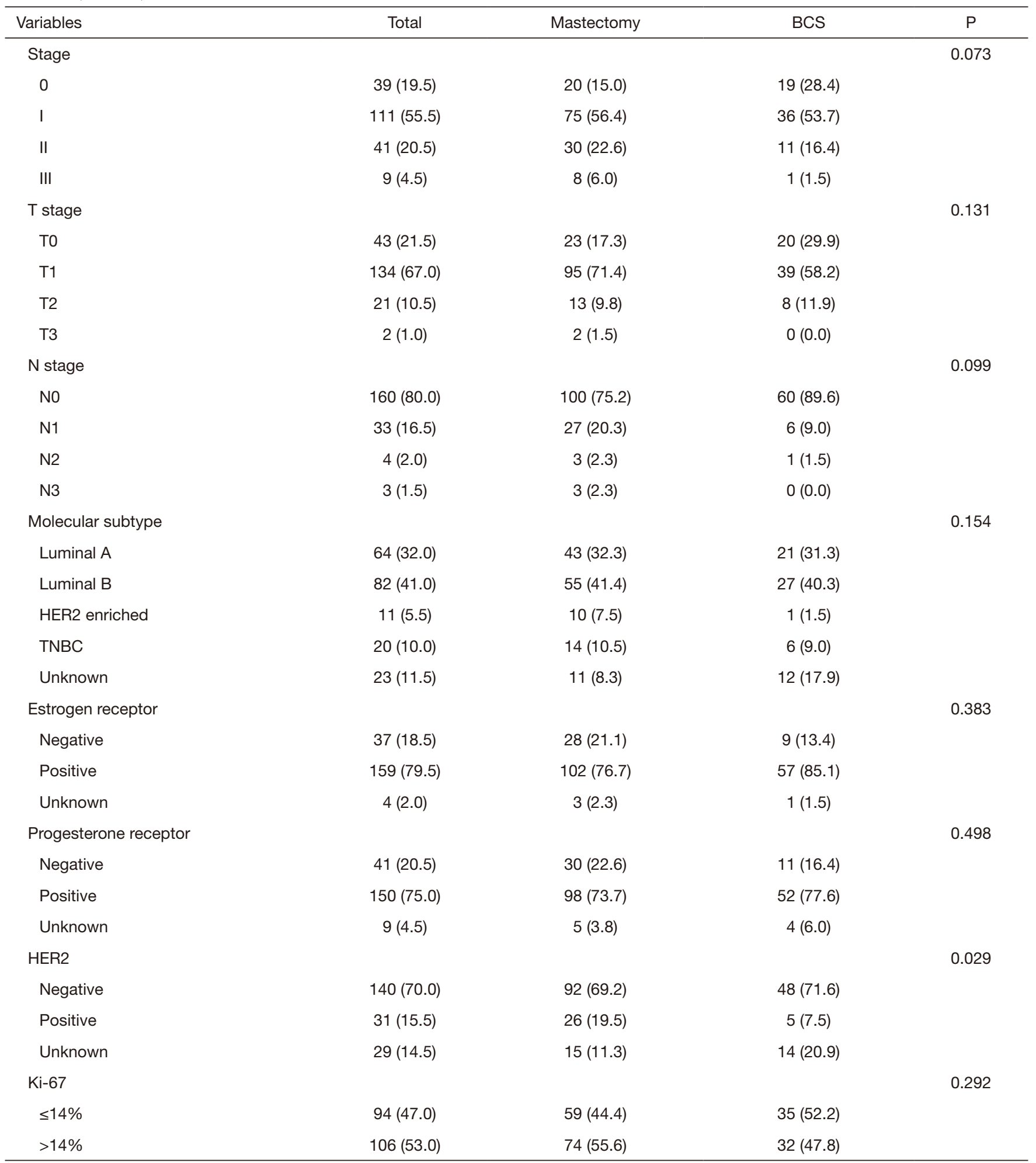

Al, aromatase inhibitor; BI-RADS, Breast Imaging Reporting and Data System; BCS, breast-conserving surgery; HER2, human epidermal growth factor receptor 2; OFS, ovarian function suppression; SD, standard deviation; SERD, selective estrogen receptor degrader. 


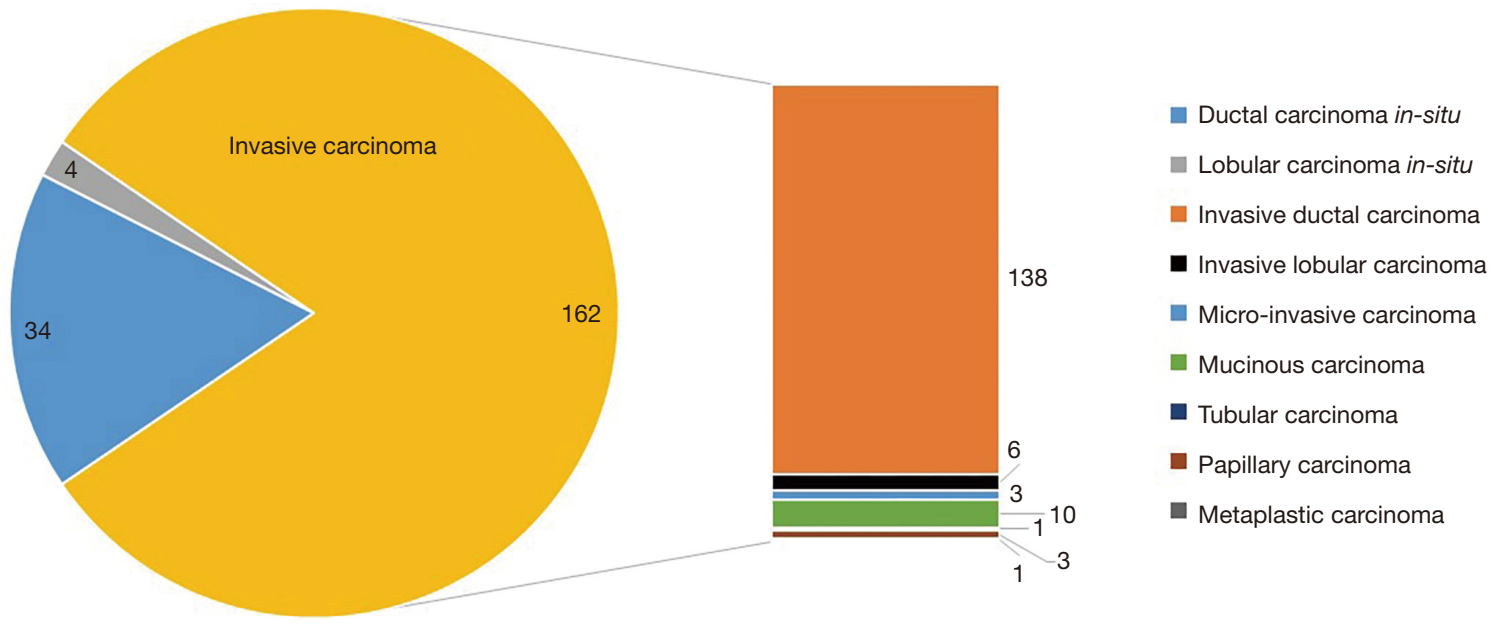

Figure 1 Pathological type of 200 breast cancer patients who undergone a Mammotome biopsy.

in TNM stage, histological type, ER, PR, HER2, molecular subtypes and therapies except for radiotherapy between these two groups (Table 1).

\section{Hematoma and tumor residual associated with Mammotome}

Among all 200 lesions biopsied by Mammotome, through the pathological report after surgery, it was found that 73 lesions had a hematoma and 143 lesions had tumor residual, accounting for $37.5 \%$ and $71.5 \%$ of all, respectively. There was no difference in the incidence of tumor residual between mastectomy and BCS group $(75.2 \%$ vs. $64.2 \%, \mathrm{P}=0.104)$; however, the incidence of hematoma in mastectomy group was significantly higher than that in BCS group (44.4\% vs. $23.9 \%, \mathrm{P}=0.005$ ) (Table 2 ).

\section{Margin status and further management in BCS}

Sixty-seven patients undergo BCS, and the margin status was shown in Table 2. Negative margin status was observed in 60 patients, accounting for $89.6 \%$ of all 67 cases. Positive status at first examination was found in 7 patients, including 5 with focal positive margin and 2 with extensive positive margin was found in 5 patients, accounting for $7.5 \%$ and $3 \%$ respectively (Table 3). Among five patients with focal positive margins, 4 received re-excision after, and one refused to receive further surgery with the strengthen radiotherapy. Two patients with extensive positive margins received mastectomy, finally including one with implant construction. The total success rate of BCS was $95.5 \%$. By the analysis of the impact of hematoma and tumor residual on margin status, we found that hematoma did not correlate with positive margin $(\mathrm{P}=0.120$, Spearman coefficient $=0.191$ ), but there is a correlation between tumor residual and margin status $(\mathrm{P}=0.037$, Spearman coefficient $=0.255)$ (Table 4).

\section{Discussion}

By reviewing 200 lesions from 198 patients with breast cancer who were diagnosed by Mammotome in other multicenters and received surgeries by pathological confirmation in our cancer center, we found that though Mammotome biopsy might lead to hematoma and tumor residual, it is not the determinant factor for surgery option. BCS is feasible through a complete excision of tumor residual to acquire a negative margin and might not be considered as a risk factor for BCS.

Though the sample size is not exceptionally large, it is reasonable. Pan et al. reviewed a total of 5,232 USVABB procedures and reported that 61 malignant lesions were identified, only accounting for $1 \%$ of all (16). This percentage indicated that there is at least a pool of 20 thousand people who received Mammotome and the situation of underestimation of the malignancy by the U.S. is rare. Our results confirmed this that $90 \%$ of the lesions were below a classification of BI-RADS 4B, indicating that most lesions presented with characteristics of benign lesions. Even confirmed as malignancy, we found that $19 \%$ of lesions were diagnosed with carcinoma in situ and earlystage 0 -II reached a percentage of $95.5 \%$, suggesting that 
A

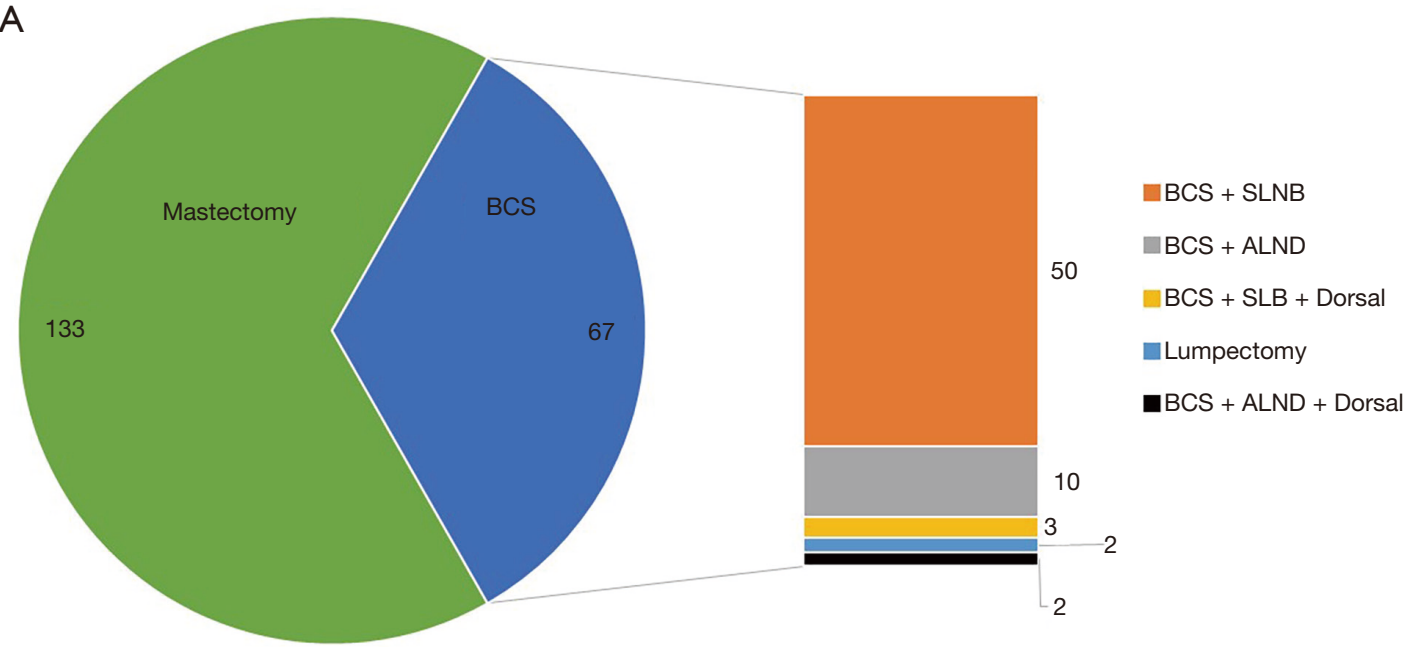

B

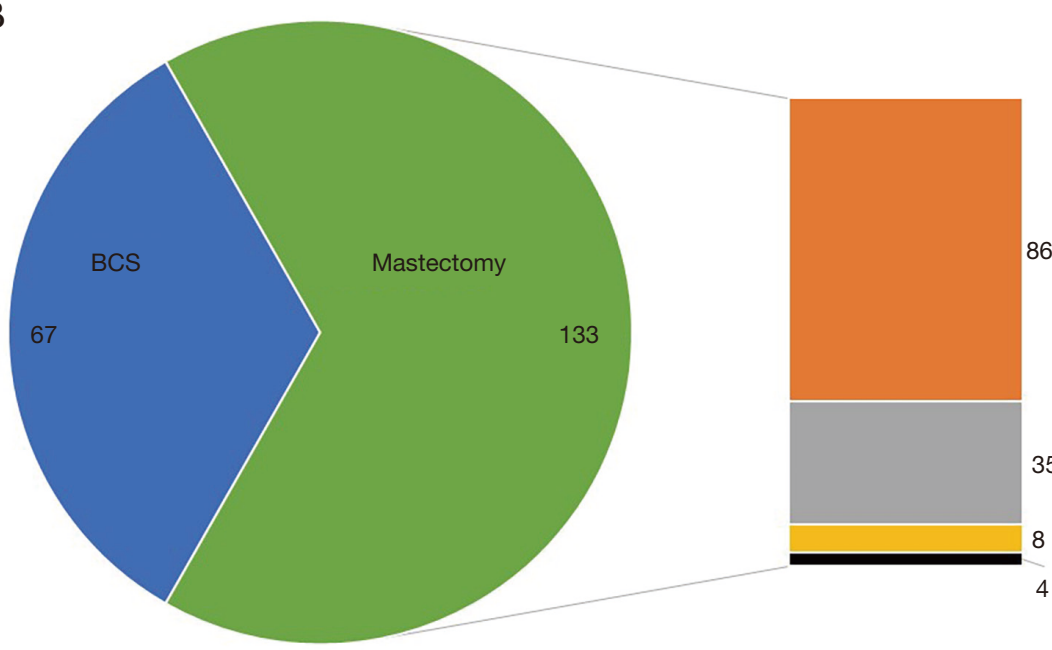

Mastectomy + ALND

Mastectomy + SLNB

Skin-spared mastectomy + SLNB + implant

35

Skin-spared mastectomy + ALND

implant

Figure 2 Details of surgery options in 200 breast cancer patients who undergone a mammotome biopsy. (A) Subclassifications of breast conserving surgery in 67 patients; (B) subclassifications of breast mastectomy in 133 patients. BCS, breast-conserving surgery; SLNB, sentinel lymph node biopsy; ALND, axillary lymph node dissection.

Table 2 Hematoma, tumor residual and surgical margin of specimens

\begin{tabular}{|c|c|c|c|c|}
\hline Variables & Total $(n=200)(\%)$ & Mastectomy $(n=133)(\%)$ & $\operatorname{BCS}(n=67)(\%)$ & $\mathrm{P}$ \\
\hline Hematoma & $75(37.5)$ & $59(44.4)$ & $16(23.9)$ & 0.005 \\
\hline Tumor residual & $143(71.5)$ & $100(75.2)$ & $43(64.2)$ & 0.104 \\
\hline \multicolumn{5}{|l|}{ Issue related to surgery } \\
\hline Negative & $60(89.6)$ & - & $60(89.6)$ & \\
\hline Single positive & $5(7.5)$ & - & $5(7.5)$ & \\
\hline Extensive positive & $2(3.0)$ & - & $2(3.0)$ & \\
\hline
\end{tabular}

BCS, breast-conserving surgery. 
Table 3 Further surgical management of 7 patients with positive margin during BCS

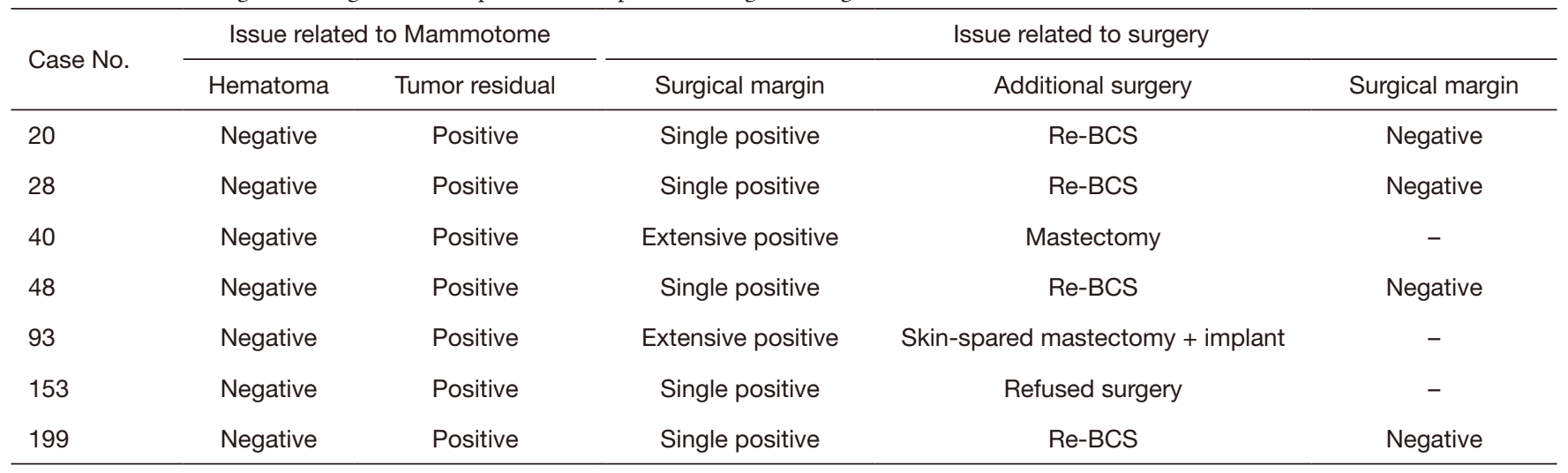

BCS, breast-conserving surgery.

Table 4 Differences and correlations between tumor residual, hematoma and surgical margin among patients treated with BCS

\begin{tabular}{|c|c|c|c|c|c|}
\hline Variables & \multicolumn{2}{|c|}{ Surgical margin } & $\mathrm{P}^{*}$ & \multicolumn{2}{|c|}{ Spearman correlation } \\
\hline \multicolumn{6}{|c|}{ Tumor residual } \\
\hline Negative & $24(40.0)$ & $0(0)$ & 0.044 & 0.255 & 0.037 \\
\hline Positive & $36(60.0)$ & $7(100.0)$ & & & \\
\hline Negative & $44(73.3)$ & $7(100.0)$ & 0.184 & 0.191 & 0.120 \\
\hline Positive & $16(26.7)$ & $0(0)$ & & & \\
\hline
\end{tabular}

*, P value was calculated using the Fisher's exact test. BCS, breast-conserving surgery.

these lesions, though malignant, were not at high-risk for recurrence and metastasis.

We noticed that the mean age of 198 patients undergone Mammotome was 42.9 years old (range, 24-73), which is consistent with another previous study (17). The younger age than that in large-scale epidemiological breast cancer study may be well explained by that young woman care more about the shape and scars than the old.

According to the NCCN guideline, the contraindications for breast-conserving therapy about the requirement for margins include the absolute with details as a widespread disease that cannot be incorporated by local excision of a single region or segment of breast tissue that achieves negative margins with a satisfactory cosmetic result, diffusely positive pathological margins and the relative with details as positive pathological margin. The way of biopsy is not in the contraindications; however, the question of whether Mammotome affected BCS through affecting margin status is unknown, which is the real meaning of this study. Among these 200 lesions, residual lesion and the hematoma was found from the specimen in $71.5 \%$ and $31.5 \%$ of all, respectively, suggesting that sometimes Mammotome could not excise the lesion completely and avoid vessels visually, which might be not superior to open excision from this point.

Mastectomy was performed in 131 patients who are not appropriate for receiving BCS based on the contraindications and the patient's willingness. In 67 patients undergone BCS, positive margin status at first examination was observed in $10.5 \%$ of patients, including four conserved the breast by the second excision and two received mastectomy due to extensive positive margins, finally. Our results showed no higher occurrence than that in previous studies, which reported that the positive rate of margins in BCS varied from $9 \%$ to $36 \%(18,19)$.

Besides mastectomy and BCS, we noticed that 17 patients 
received breast reconstruction at the same time. Pedicled descending branch latissimus dorsi mini flap is used in BCS to guarantee a satisfactory cosmetic result, in the situation of extensively lesions, hematoma or far distance from lesion to Mammotome biopsy spot, that has been reported by our department previously $(20,21)$. For those widespread diseases and diffuse microcalcifications, the nipple-areola complex and skin spared mastectomy combined with breast implants might be an appropriate alternative way.

Our study, though answered a clinical question, has some limitations. First, this is a retrospective study, which may have some bias. We once plan to carry out a prospective one, but due to the uncertainty of underestimation on malignancy by ultrasound, it is hard to perform in practice. Second, though these patients received further surgeries in our cancer center, they have undergone Mammotome biopsy in multi-centers, which may affect the consistency of this procedure.

In conclusion, our research explored the impact of Mammotome biopsy on the surgery option and margin status during breast conserving surgery in breast cancer that was underestimated by the U.S., which has never been studied before. We found that although Mammotome biopsy for underestimated malignancy might lead to hematoma and tumor residual, it is not the determinant factor for surgery option and BCS is feasible through a complete excision of tumor residual to acquire negative margin, which may give some help to the surgeon that BCS still could be recommended to those patients when they pursue beauty but worry about the safety.

\section{Acknowledgments}

We would like to thank Mr. Delicati Kingsham for his help in polishing our paper.

Funding: None.

\section{Footnote}

Reporting Checklist: The authors have completed the STROBE reporting checklist. Available at https://dx.doi. org/10.21037/gs-20-701

Data Sharing Statement: Available at https://dx.doi. org/10.21037/gs-20-701

Conflicts of Interest: All authors have completed the ICMJE uniform disclosure form (available at https://dx.doi. org/10.21037/gs-20-701). The authors have no conflicts of interest to declare.

Ethical Statement: The authors are accountable for all aspects of the work in ensuring that questions related to the accuracy or integrity of any part of the work are appropriately investigated and resolved. The study was conducted in accordance with the Declaration of Helsinki (as revised in 2013). The study was approved by institutional ethics board and informed consent was taken from all the patients.

Open Access Statement: This is an Open Access article distributed in accordance with the Creative Commons Attribution-NonCommercial-NoDerivs 4.0 International License (CC BY-NC-ND 4.0), which permits the noncommercial replication and distribution of the article with the strict proviso that no changes or edits are made and the original work is properly cited (including links to both the formal publication through the relevant DOI and the license). See: https://creativecommons.org/licenses/by-nc-nd/4.0/.

\section{References}

1. Abbate F, Cassano E, Menna S, et al. Ultrasoundguided vacuum-assisted breast biopsy: Use at the European Institute of Oncology in 2010. J Ultrasound 2011;14:177-81.

2. Meyer JE, Smith DN, Lester SC, et al. Large-core needle biopsy of nonpalpable breast lesions. JAMA 1999;281:1638-41.

3. Simon JR, Kalbhen CL, Cooper RA, et al. Accuracy and complication rates of US-guided vacuum-assisted core breast biopsy: initial results. Radiology 2000;215:694-7.

4. Yu YH, Liang C, Yuan XZ. Diagnostic value of vacuumassisted breast biopsy for breast carcinoma: a metaanalysis and systematic review. Breast Cancer Res Treat 2010;120:469-79.

5. Hopper KD, Baird DE, Reddy VV, et al. Efficacy of automated biopsy guns versus conventional biopsy needles in the pygmy pig. Radiology 1990;176:671-6.

6. Povoski SP, Jimenez RE, Wang WP. Ultrasound-guided diagnostic breast biopsy methodology: retrospective comparison of the 8-gauge vacuum-assisted biopsy approach versus the spring-loaded 14-gauge core biopsy approach. World J Surg Oncol 2011;9:87.

7. Suh YJ, Kim MJ, Kim EK, et al. Comparison of the underestimation rate in cases with ductal carcinoma in situ 
at ultrasound-guided core biopsy: 14-gauge automated core-needle biopsy vs 8- or 11-gauge vacuum-assisted biopsy. Br J Radiol 2012;85:e349-56.

8. Verkooijen HM, Borel Rinkes IH, Peeters PH, et al. Impact of stereotactic large-core needle biopsy on diagnosis and surgical treatment of nonpalpable breast cancer. Eur J Surg Oncol 2001;27:244-9.

9. Surgeons TASoB. Performance and Practice Guidelines for Stereotactic Breast Procedures. Revised April 28 2010. Official Statements. Available online: https://www. breastsurgeons.org/resources/statements, accessed Feb 01 2020.

10. Povoski SP, Jimenez RE. A comprehensive evaluation of the 8-gauge vacuum-assisted Mammotome(R) system for ultrasound-guided diagnostic biopsy and selective excision of breast lesions. World J Surg Oncol 2007;5:83.

11. Grady I, Gorsuch H, Wilburn-Bailey S. Long-term outcome of benign fibroadenomas treated by ultrasoundguided percutaneous excision. Breast J 2008;14:275-8.

12. Iwuagwu O, Drew P. Vacuum-assisted biopsy devicediagnostic and therapeutic applications in breast surgery. Breast 2004;13:483-7.

13. Radiology ACo. ACR BI-RADS®—mammography. In: D’Orsi CJ, Sickles EA, Mendelson EB, et al. editors. ACR BI-RADS Atlas: Breast Imaging Reporting and Data System. 5th ed. Reston, VA: American College of Radiology, 2013:1-175.

14. Goldhirsch A, Wood WC, Coates AS, et al. Strategies for subtypes--dealing with the diversity of breast cancer: highlights of the St. Gallen International Expert

Cite this article as: Kong Y, Lyu N, Wang J, Wang Y, Sun Y, Xie Z, Liu P. Does Mammotome biopsy affect surgery option and margin status of breast conserving surgery in breast cancer? Gland Surg 2021;10(8):2428-2437. doi: 10.21037/gs-20-701
Consensus on the Primary Therapy of Early Breast Cancer 2011. Ann Oncol 2011;22:1736-47.

15. Giordano SH, Elias AD, Gradishar WJ. NCCN Guidelines Updates: Breast Cancer. J Natl Compr Canc Netw 2018;16:605-10.

16. Pan S, Liu W, Jin K, et al. Ultrasound-guided vacuumassisted breast biopsy using Mammotome biopsy system for detection of breast cancer: results from two high volume hospitals. Int J Clin Exp Med 2014;7:239-46.

17. Kong Y, Yang L, Tang H, et al. A nation-wide multicenter retrospective study of the epidemiological, pathological and clinical characteristics of breast cancer in situ in Chinese women in 1999 - 2008. PLoS One 2013;8:e81055.

18. Brouwer de Koning SG, Vrancken Peeters MTFD, Jóźwiak K, et al. Tumor Resection Margin Definitions in Breast-Conserving Surgery: Systematic Review and Metaanalysis of the Current Literature. Clin Breast Cancer 2018;18:e595-600.

19. Gray RJ, Pockaj BA, Garvey E, et al. Intraoperative Margin Management in Breast-Conserving Surgery: A Systematic Review of the Literature. Ann Surg Oncol 2018;25:18-27.

20. Zhou L, Wang Y, Cai R, et al. Pedicled descending branch latissimus dorsi mini-flap in repairing partial mastectomy defect: Shoulder functional and esthetic outcomes. J Surg Oncol 2019;120:518-26.

21. Cai R, Xie Z, Zhou L, et al. Pedicled Descending Branch Latissimus Dorsi Mini-flap for Repairing Partial Mastectomy Defect: A New Technique. Plast Reconstr Surg Glob Open 2018;6:e1692. 